\title{
EUS-B for suspected left adrenal metastasis in lung cancer
}

\author{
Ida Skovgaard Christiansen ${ }^{1,2 \#}$, Khaliq Ahmad ${ }^{2 \#}$, Uffe Bodtger ${ }^{1,2,3}$, Therese Maria Henriette Naur, \\ Jatinder Singh Sidhu ${ }^{2}$, Rafi Nessar ${ }^{1}$, Goran Nadir Salih ${ }^{1}$, Asbjørn Høegholm ${ }^{2}$, Jouke Tabe Annema ${ }^{5}$, \\ Paul Frost Clementsen ${ }^{1,4,6}$
}

${ }^{1}$ Department of Internal Medicine, Unit of Respiratory Medicine, Zealand University Hospital, Roskilde, Denmark; ${ }^{2}$ Department of Respiratory Medicine, Næstved Hospital, Næstved, Denmark; ${ }^{3}$ Institute for Regional Health Research, University of Southern Denmark, Odense C, Denmark; ${ }^{4}$ Copenhagen Academy for Medical Education and Simulation (CAMES), Rigshospitalet, University of Copenhagen, Copenhagen, Denmark; ${ }^{5}$ Department of Respiratory Medicine, Academic Medical Center, Amsterdam, The Netherlands; ${ }^{6}$ Department of Clinical Medicine, University of Copenhagen, Copenhagen, Denmark

Contributions: (I) Conception and design: IS Christiansen, K Ahmad, U Bodtger, PF Clementsen; (II) Administrative support: TMH Naur, JS Sidhu; (III) Provision of study materials or patients: U Bodtger, JS Sidhu, R Nessar, GN Salih, A Høegholm; (IV) Collection and assembly of data: IS Christiansen, K Ahmad; (V) Data analysis and interpretation: IS Christiansen, TMH Naur, U Bodtger, JT Annema, PF Clementsen; (VI) Manuscript writing: All authors; (VII) Final approval of manuscript: All authors.

\#These authors contributed equally to this work.

Correspondence to: Ida Skovgaard Christiansen, MD. Department of Internal Medicine, Zealand University Hospital, Sygehusvej 10, 4000 Roskilde, Denmark. Email: ida.skovgaard@gmail.com.

Background: Several studies have reported the efficacy of esophageal ultrasound-guided fine needle aspiration (EUS-FNA) for the detection of metastases in the left adrenal gland (LAG) in patients with lung cancer. Currently we have only limited evidence based on small studies on the usefulness of EUS-B [endobronchial ultrasound (EBUS) scope into the esophagus] to provide tissue proof of suspected LAG metastases. The objectives of this study are to investigate feasibility, safety and diagnostic yield of EUS-BFNA in LAG analysis in patients with proven or suspected lung cancer.

Methods: In two Danish hospitals, a systematic search in the electronic database for patients who underwent EUS-B-FNA of the LAG for suspected or proven lung cancer was performed retrospectively between January 1st, 2015 and December 31st, 2017. Computed tomography (CT), positron emission tomography-CT, endoscopy, pathology and follow-up data were acquired.

Results: One hundred and thirty-five patients were included; the prevalence of biopsy proven LAG malignancy was $30 \%(40 / 135)$. A total of $87 \%$ (117/135) of EUS-B-FNA samples were adequate (i.e., containing adrenal or malignant cells). No complications were observed.

Conclusions: We present the largest cohort of patients ever reported showing that EUS-B-FNA of the LAG is a safe and feasible procedure and should therefore be used for staging purposes in patients with lung cancer and a suspicious LAG.

Keywords: Lung cancer; endobronchial ultrasound (EBUS); esophageal ultrasound (EUS); EUS-B; left adrenal gland (LAG)

Submitted Jul 03, 2019. Accepted for publication Nov 09, 2019.

doi: $10.21037 /$ jtd.2020.01.43

View this article at: http://dx.doi.org/10.21037/jtd.2020.01.43

\section{Introduction}

Lung cancer is the most commonly diagnosed cancer and the most frequent cause of cancer death and unfortunately, the prognosis is poor (1). Most cases are non-small cell lung cancer (NSCLC). Accurate staging of NSCLC is crucial for allocation to surgical treatment, which is curative only in cases of localized disease. The recommended treatment of 
disseminated NSCLC and of small cell lung cancer involves chemotherapy and radiation therapy. Staging is based on three components: $\mathrm{T}$ (the extent of the primary tumor), $\mathrm{N}$ (involvement of lymph nodes), and $M$ (distant metastases). The clinical stage (cTNM) is determined before initiation of treatment and is based on any available information for example computed tomography (CT) and positron emission tomography-CT (PET-CT).

The $M$ component is subdivided into intrathoracic dissemination (M1a), a single extrathoracic metastasis (M1b), and multiple metastases (M1c) (2). The adrenal glands are common sites of lung cancer metastasis. Adrenal masses are found in up to $4-7 \%$ of patients with potentially resectable lung cancer (3). Approximately two thirds of these masses are benign adenomas (4). Therefore, pathological verification of a suspicious adrenal gland is mandatory for correct TNM classification and for correct treatment of the patient. Endobronchial ultrasound-guided transbronchial needle aspiration (EBUS-TBNA) and esophageal ultrasound-guided fine needle aspiration (EUSFNA) have high accuracy for demonstrating lung cancer and lymph node metastases $(5,6)$. Furthermore, several studies have reported the efficacy of EUS-FNA for the detection of metastases in the left adrenal gland (LAG) in patients with lung cancer (7-13). The European Guidelines recommend endosonography for tissue verification from LAG lesions suspected of metastases (5).

EUS-FNA can be performed either with the use of a conventional gastrointestinal ultrasound scope (EUS) or by using the EBUS-scope in the esophagus (EUS-B) (5). EUS-FNA is known to be able to provide tissue samples of lesions below the diaphragm including the LAG (12). EUSB-FNA has been shown to have equal diagnostic properties to EUS-FNA in diagnosing LAG lesions (13). However, EUS-B-FNA is a relatively novel technique. Therefore, the literature gives us limited access to experience. On this background we want to describe the largest cohort ever reported of patients with suspected lung cancer having the LAG biopsied by EUS-B-FNA.

\section{Methods}

In two centres (Department of Internal Medicine, Næstved Hospital, Denmark and Department of Internal Medicine, Zealand University Hospital, Roskilde, Denmark) a retrospective systematic search was performed in the hospitals' electronic databases on all consecutive patients who underwent a tissue sample from the LAG with EUS-B-
FNA for suspected or proven lung cancer between January 1st, 2015 and December 31st, 2017.

EUS-B-FNA sampling of the LAG was performed if a suspicious lesion was present, indicated by either increased metabolic activity at PET, or abnormal appearance at CT or EUS-B (if the LAG appeared enlarged, with loss of seagull sign or in any other way abnormal). Cytological results of the samples were registered and tissue samples were considered adequate when adrenal cells or malignant cells were demonstrated in the sample.

For adequate samples with non-malignant diagnoses at cytopathological evaluation, the results of the biopsies were considered true-negative by at least 6 months follow up (clinical course and/or CT) both for patients with and without lung cancer if clinically relevant.

Sensitivity of malignancy was defined as the number of samples in which EUS-B-FNA provided a diagnosis of any malignancy relative to the total number of targeted lesions that turned out to be malignant (14). By "worst-case" scenario, we understand a scenario were all patients with inconclusive samples or no follow-up are suffering from malignant disease.

By "best-case" scenario, we understand a scenario were only patients with biopsy-proven malignancy are suffering from malignant disease.

Diagnostic yield was defined as the number of samples in which EUS-B-FNA provided a specific diagnosis (malignant or non-malignant) relative to the total number of samples performed with EUS-B-FNA (14).

Data were non-parametric and presented with median and range. Data were processed using SPSS. (IBM SPSS Statistics, version 25. Chicago, IL, USA).

\section{The EUS-B procedure}

EUS-B was performed as a part of the endoscopic work up combined with EBUS-TBNA according to the European guideline (5). Initially a bronchoscopy and an EBUS procedure according to a structured protocol as described by Konge et al. $(11,15)$ were performed with the patient in a supine position under conscious sedation. Either a nasal or oral approach was used. Thereafter the EBUS endoscope was retracted from the trachea to a level just above the vocal cords and from this position turned slightly to the left and the back of the patient and advanced into the esophagus under gentle pressure while the patient was encouraged to swallow. Continuous ultrasound imaging was performed and the endoscope was advanced very carefully without pressure to a level below the diaphragm. Five milliliter $4 \%$ 
Table 1 Demographic data and final diagnosis of patients

\begin{tabular}{lc}
\hline Variables & Number \\
\hline Number of patients, $n$ & 135 \\
Gender: female & $85(63 \%)$ \\
Age, median [95\% percentile] & $69[50-84]$ \\
Final diagnosis after complete work up & \\
Primary pulmonary cancer & $102(76 \%)$ \\
NSCLC & \\
$\quad$ Adenocarcinoma & $62(46 \%)$ \\
$\quad$ Squamous cell carcinoma & $17(13 \%)$ \\
$\quad$ NSCLC-NOS & $10(7 \%)$ \\
SCLC & $12(9 \%)$ \\
Large cell neuroendocrine carcinoma & $1(1 \%)$ \\
Metastasis from extra pulmonary tumor & $10 *(7 \%)$ \\
Lymphoma & $4(3 \%)$ \\
Non-malignant & $19(14 \%)$ \\
\hline * from colon: 3, upper gastrointestinal tract: 1, pancreas: 1, \\
mammae: 1 , uterus: 1 ; hepatocellular carcinoma: 1, malignant \\
melanoma: 1 , origin of primary tumor never found: 1. NSCLC, \\
non-small cell lung cancer; NSCLC-NOS, non-small cell lung \\
cancer not otherwise specified; SCLC, small cell lung cancer.
\end{tabular}

Table 2 EUS-B-FNA results of left adrenal gland sampling ( $\mathrm{n}=135)$

\begin{tabular}{lc}
\hline Variables & Number \\
\hline $\begin{array}{l}\text { Cytopathological results of samples from the } \\
\text { left adrenal gland }\end{array}$ & 135 \\
Adequate samples* & $117(87 \%)$ \\
Cytopathological diagnosis of adequate & \\
samples & $77(66 \%)$ \\
Non-malignant & $40(34 \%)$ \\
\hline
\end{tabular}

*, tissue samples were considered adequate when adrenal cells or malignant cells were demonstrated in the sample.

Lidocaine was applied to the pharynx and larynx prior to the EUS-B procedure. A structured protocol was followed using an EUS assessment tool (EUS-AT) $(11,15,16)$ with six landmarks identified in this order: the liver, the abdominal aorta, the LAG, lymph node station 7, station $4 \mathrm{~L}$ and $4 \mathrm{R}$. When an abnormal LAG was demonstrated, a biopsy was taken by introducing the needle through the biopsy channel of the endoscope. Power Doppler was used to prevent puncture of vessels. The tip of the needle was placed in the lesion under real-time ultrasonic guidance and the stylet was then removed. Suction was applied with a syringe and the needle was moved back and forth inside the lesion. At least two samples were taken and the aspirates were processed for both cytological smears and cell block analysis. EUS-B was performed with a flexible ultrasound bronchoscope (Olympus BF-UC180F or UC 180F, Olympus Medical Systems Europe, Ltd., Hamburg) in combination with a Hitachi ultrasound scanner (EUB 6500 or Hivision Preirus, model EZU-MT28-S1) with a linear scanning transducer. A $19 \mathrm{G}$, a $22 \mathrm{G}$ or a $25 \mathrm{G}$ needle was used for the aspirations (ViziShot Flex 19 Gauge, 22 Gauge Olympus ViziShot and ViziShot 2. Olympus Medical Systems Europe, Ltd., Hamburg, Germany).

\section{Ethics}

The study was a retrospective observational study without experimental procedures. The study does not fall under the jurisdiction of the scientific ethics system. The study was approved by the Danish Data Protection Agency.

\section{Results}

A total of 135 patients with the LAG sampled with EUS-BFNA were identified in our systematic search. Demographic data and final diagnosis of work-up are shown in Table 1.

At final diagnosis, 116 patients had a diagnosis of a malignant disease, mostly lung cancer. Of the 19 patients with non-malignant diagnoses after complete work up, at least 6 months follow up without subsequent finding of malignant disease was performed in all patients (10 followed with clinical course, 9 with clinical course and CT). No severe adverse events were recorded for any patients.

A total of $87 \%(117 / 135)$ of the samples were adequate (i.e., containing adrenal cells or malignant cells) at cytopathological evaluation (Table 2): the prevalence of malignancy in the LAG was $30 \%$ (40/135). In 35 of these 40 patients, the malignant lesion was a metastasis from primary pulmonary cancer, in five patients the malignant lesion was a metastasis from an extra thoracic malignancy. No benign, specific diagnoses were made therefore diagnostic yield was 30\% (40/135).

Of the remaining 77 patients with a non-malignant cytopathological finding, follow-up for the LAG lesion was not possible in 51 patients as final work-up showed disseminated malignant disease, and the patients were 
Table 3 Characteristics of left adrenal gland at CT, PET and EUS-B

\begin{tabular}{lc}
\hline Variables & Number \\
\hline Number of samples & 135 \\
CT performed, $\mathrm{n}$ & 135 \\
LAG suspicious at CT* & $114(84.4 \%)$ \\
LAG not suspicious at CT & $21(15.6 \%)$ \\
Samples with PET performed, $\mathrm{n}$ & 74 \\
LAG suspicious at PET** & $30(40.5 \%)$ \\
LAG not suspicious at PET & $44(59.5 \%)$ \\
LAG in EUS-B description, $\mathrm{n}$ & 110 \\
LAG described suspicious on EUS-B & $91(82.7 \%)$ \\
LAG not suspicious on EUS-B & $19(17.3 \%)$ \\
\hline
\end{tabular}

*, CT and EUS-B suspicious when abnormal appearance (left adrenal gland enlarged, loss of seagull sign or in any other way abnormal); **, PET suspicious when increased metabolic activity. LAG, left adrenal gland.

offered systemic, oncological treatment.

Follow-up of the LAG lesion was completed in 26 patients without a diagnosis of cancer (clinical course $\mathrm{n}=13$; clinical course and CT: $\mathrm{n}=13$ ). Thus, in the best-case scenario, the negative predictive value (NPV) in patients without disseminated malignant disease plus 6-months follow-up was $100 \%$. In a worst-case scenario where the 51 patients without follow-up were considered false-negative, the NPV would be $34 \%$ (26/77).

Concerning the 18 inadequate samples, one patient had malignancy at re-EUS-B of the LAG, in 11 patients resampling was irrelevant due to disseminated malignant disease, and in 6 patients, 6-months follow-up was without a diagnosis of cancer.

Thus, sensitivity of malignancy was $39 \%$ in a worst-case scenario [40 malignant/103 (=40 malignant +63 samples without follow-up)], and $98 \%$ in a best-case scenario [40/41 (=40 malignant at initial EUS-B + 1 malignant at reexamination)].

The characteristics of LAG on CT, PET and EUS-B are shown in Table 3. Of the 44 patients with normal metabolic activity of the LAG on PET the lesion proved malignant in a single case.

\section{Discussion}

The main finding of our study is that EUS-B-guided biopsy from the LAG is a safe and feasible technique when used as a routine in the hands of chest physicians in the diagnosing and staging of patients with lung cancer.

The current cohort of patients is by far the largest $(n=135)$ ever reported, and the malignancy detection rate of EUS-BFNA was high.

There is growing evidence of the value of EUS-B for mediastinal staging of lung cancer patients. However, we have very limited data concerning the role of EUS-B for staging of patients with lesions below the diaphragm.

The LAG has been shown to be visualized and biopsied with EUS-B $(13,17)$ in smaller cohorts. Crombag et al. found in a retrospective setting 9 cases with tissue biopsy (17) and in a prospective setting tissue biopsy from 44 cases (13). Crombag et al. found that the success rate of EUS-B-FNA of LAG was comparable to conventional EUS-FNA (13). It should be noted that in these and the present study the length of the relatively short EBUSscope, compared to the EUS-scope, was not a limiting factor. Our data supports, with a large number of LAG samples, the ability of EUS-B to visualize and biopsy this structure.

In the analysis of sensitivity of malignancy and the NPV a group of samples from 51 patients it was not possible to perform the 6-month follow-up to show if the sample was true or false negative, since in all of these patients systemic oncological treatment of the disseminated disease was given. This relatively large number has a big influence on calculations.

Calculations of sensitivity and NPV were performed both with these samples calculated as false negative, worst case scenario, (NPV 34\%, sensitivity 39\%) and in a best-case scenario (NPV 100\%, sensitivity 98\%). The true estimates must be placed somewhere in between. This weakness of the study is balanced by the strength of being able to demonstrate the value of the biopsies in a large consecutive, unselected cohort of patients in lung cancer work-up.

The sample adequacy of $87 \%$ is in line with earlier findings for EUS-B-FNA as Crombag et al. (13) found a sensitivity of $86 \%$ for LAG lesions.

The EUS endoscope traditionally used by the gastroenterologist is excellent for the left and lower paraesophageal structures and structures below the diaphragm such as the LAG, whereas the EBUS endoscope provides access to structures close to the large airways (5,9-11). It is known that EUS-B-FNA with the EBUS endoscope in the esophagus is useful as a supplement to an endobronchial approach for additional sampling of mediastinal nodes 
$(5,18-21)$ and the technique has also been shown to give assess to tissue samples from intrapulmonary tumors (22).

There are several technical advantages in the use of a conventional EUS-endoscope compared to EBUSendoscope for the esophageal approach, e.g. better stability in the stomach and the larger ultrasound device. The barriers of use of the EUS-endoscope in lung cancer workup are that most pulmonologists are not trained using the EUS-endoscope and that it requires another investment in the department already performing EBUS. Of these reasons, EUS-B-FNA is quickly gaining ground in Europe. Currently, one single endoscope that combines the features of the EUS scope mentioned with the EBUS scope designed for both esophagus and trachea does not exist.

Though inclusion in this study was consecutive, a limitation is a selection bias due to the retrospective design. Subsequent studies should include larger cohorts in a prospective multi-centre design including exclusively consecutive patients including prevalence of missed EUSB-FNA procedures due to inability to reach, visualize and/ or sample the LAG.

Our results underline that EUS-B enables the pulmonologist to biopsy lesions in the LAG and thus EUS-B provides tissue proof of potential M1 lesions below the diaphragm.

In the future, interventional pulmonologists should be trained in both EBUS-TBNA (15) and EUS-B-FNA as recommended in the guidelines (5). Especially EUS-Bguided biopsy from the LAG should be learned.

\section{Conclusions}

LAG analysis in lung cancer patients can be performed safely with EUS-B-FNA. Therefore, its use should be considered in appropriate lung cancer staging cases. The single EBUS scope approach for both nodal and LAG staging provides obvious logistical and practical advantages.

\section{Acknowledgments}

Funding: None.

\section{Footnote}

Conflicts of Interest: The authors have no conflicts of interest to declare.

Ethical Statement: The authors are accountable for all aspects of the work in ensuring that questions related to the accuracy or integrity of any part of the work are appropriately investigated and resolved. The study was approved by the Danish Data Protection Agency (No. REG-085-2015).

Open Access Statement: This is an Open Access article distributed in accordance with the Creative Commons Attribution-NonCommercial-NoDerivs 4.0 International License (CC BY-NC-ND 4.0), which permits the noncommercial replication and distribution of the article with the strict proviso that no changes or edits are made and the original work is properly cited (including links to both the formal publication through the relevant DOI and the license). See: https://creativecommons.org/licenses/by-nc-nd/4.0/.

\section{References}

1. Ferlay J, Shin HR, Bray F, et al. Estimates of worldwide burden of cancer in 2008: GLOBOCAN 2008. Int J Cancer 2010;127:2893-917.

2. Detterbeck FC, Boffa DJ, Kim AW, et al. The 8th Edition Lung Cancer Stage Classification. Chest 2016;151:193-203.

3. Chapman GS, Kumar D, Redmond J, et al. Upper abdominal computerized tomography scanning in staging non-small cell lung carcinoma. Cancer 1984;54:1541-3.

4. Ettinghausen SE, Burt ME. Prospective evaluation of unilateral adrenal masses in patients with operable nonsmall-cell lung cancer. J Clin Oncol 1991;9:1462-6.

5. Vilmann P, Frost Clementsen P, Colella S, et al. Combined endobronchial and esophageal endosonography for the diagnosis and staging of lung cancer: European society of gastrointestinal endoscopy (ESGE) guideline, in cooperation with the european respiratory society (ERS) and the european society of thor. Eur J Cardiothorac Surg 2015;48:1-15.

6. Vilmann P, Annema J, Clementsen P. Endosonography in bronchopulmonary disease. Best Pract Res Clin Gastroenterol 2009;23:711-28.

7. Varela-Lema L, Fernandez-Villar A, Ruano-Ravina A. Effectiveness and safety of endobronchial ultrasoundtransbronchial needle aspiration: A systematic review. Eur Respir J 2009;33:1156-64.

8. Annema JT, van Meerbeeck JP, Rintoul RC, et al. Mediastinoscopy vs Endosonography for Mediastinal Nodal Staging of Lung Cancer. JAMA 2010;304:2245.

9. Colella S, Clementsen PF, Gurioli C, et al. Endobronchial- 
ultrasound needle aspiration and endoscopic ultrascoundfine-needle aspiration in thoracic diseases. Pathologica 2016;108:59-79.

10. Dietrich CF, Annema JT, Clementsen P, et al. Ultrasound techniques in the evaluation of the mediastinum, part I: Endoscopic ultrasound (EUS), endobronchial ultrasound (EBUS) and transcutaneous mediastinal ultrasound (TMUS), introduction into ultrasound techniques. J Thorac Dis 2015;7:E311-25.

11. Jenssen C, Annema JT, Clementsen P, et al. Ultrasound techniques in the evaluation of the mediastinum, part 2: mediastinal lymph node anatomy and diagnostic reach of ultrasound techniques, clinical work up of neoplastic and inflammatory mediastinal lymphadenopathy using ultrasound techniques and h. J Thorac Dis 2015;7:E439-58.

12. Polkowski M, Larghi A, Weynand B, et al. Learning, techniques, and complications of endoscopic ultrasound (EUS) -guided sampling in gastroenterology : European Society of Gastro- intestinal Endoscopy (ESGE) Technical Guideline. Endoscopy 2012;44:190-206.

13. Crombag LMMJ, Szlubowski A, Stigt JA, et al. EUSB-FNA vs conventional EUS-FNA for left adrenal gland analysis in lung cancer patients. Lung Cancer 2017;108:38-44.

14. Korevaar DA, Colella S, Spijker R, et al. Esophageal Endosonography for the Diagnosis of Intrapulmonary Tumors: A Systematic Review and Meta-Analysis. Respiration 2017;93:126-37.

15. Konge L, Clementsen PF, Ringsted C, et al. Simulator training for endobronchial ultrasound: A randomised controlled trial. Eur Respir J. 2015;46:1140-9.

Cite this article as: Christiansen IS, Ahmad K, Bodtger U, Naur TMH, Sidhu JS, Nessar R, Salih GN, Høegholm A, Annema JT, Clementsen PF. EUS-B for suspected left adrenal metastasis in lung cancer. J Thorac Dis 2020;12(3):258-263. doi: $10.21037 /$ jtd.2020.01.43
16. Konge L, Vilmann P, Clementsen P, et al. Reliable and valid assessment of competence in endoscopic ultrasonography and fine-needle aspiration for mediastinal staging of non-small cell lung cancer. Endoscopy 2012;44:928-33.

17. Crombag LMMJ, Annema JT. Left Adrenal Gland Analysis in Lung Cancer Patients Using the Endobronchial Ultrasound Scope: A Feasibility Trial. Respiration 2016;91:235-40.

18. Hwangbo B, Lee GK, Lee HS, et al. Transbronchial and transesophageal fine-needle aspiration using an ultrasound bronchoscope in mediastinal staging of potentially operable lung cancer. Chest 2010;138:795-802.

19. Hwangbo B, Lee HS, Lee GK, et al. Transoesophageal needle aspiration using a convex probe ultrasonic bronchoscope. Respirology 2009;14:843-9.

20. Wimaleswaran H, Farmer MW, Irving LB, et al. Pulmonologist-performed transoesophageal sampling for lung cancer staging using an endobronchial ultrasound video-bronchoscope: an Australian experience. Intern Med J 2017;47:205-10.

21. Herth FJF, Krasnik M, Kahn N, et al. Combined endoscopic-endobronchial ultrasound-guided fine-needle aspiration of mediastinal lymph nodes through a single bronchoscope in 150 patients with suspected lung cancer. Chest 2010;138:790-4.

22. Steinfort DP, Farmer MW, Irving LB, et al. Pulmonologist-performed Per-Esophageal Needle Aspiration of Parenchymal Lung Lesions Using an EBUS Bronchoscope. J Bronchology Interv Pulmonol 2017;24:117-24. 